\title{
Policy Levers Key for Primary Health Care Organizations to Support Primary Care Practices in Meeting Medical Home Expectations: Comparing Leading States to the Australian Experience
}

\author{
Mary Takach, MPH, $\mathrm{RN}^{1}$
}

\begin{abstract}
Several countries with highly ranked delivery systems have implemented locally-based, publicly-funded primary health care organizations (PHCOs) as vehicles to strengthen their primary care foundations. In the United States, state governments have started down a similar pathway with models that share similarities with international PHCOs. The objective of this study was to determine if these kinds of organizations were working with primary care practices to improve their ability to provide comprehensive, coordinated, and accessible patientcentered care that met quality, safety, and efficiency outcomes - all core attributes of a medical home. This qualitative study looked at 4 different PHCO models-3 from the United States and 1 from Australia-with similar objectives and scope. Primary and secondary data included semi-structured interviews with 26 PHCOs and a review of government documents. The study found that the 4 PHCO models were engaging practices to meet a number of medical home expectations, but the US PHCOs were more uniform in efforts to work with practices and focused on arranging services to meet the needs of complex patients. There was significant variation in level of effort between the Australian PHCOs. These differences can be explained through the state governments' selection of payment models and use of data frameworks to support collaboration and incentivize performance of both PHCOs and practices. These findings offer policy lessons to inform health reform efforts under way to better capitalize on the potential of PHCOs to support a high-functioning primary health foundation as an essential component to a reformed health system.
\end{abstract}

\section{Introduction}

$\mathbf{H}$ EALTH SYSTEMS ACROSS THE WORLD are under extraordinary pressure to evolve to respond to the demands of an aging population, growing numbers of people living with chronic illnesses, and a steady growth in health spending. ${ }^{1}$ Responding to these demands will require innovative strategies aimed at the primary care foundation, which is the "most efficient structure" for managing a large majority of the patient's needs and coordinating care for patients across the complex delivery system. ${ }^{2}$

Countries with highly ranked delivery systems, including Australia, New Zealand, and the United Kingdom, ${ }^{3}$ have supported the development of primary health care organiza- tions (PHCOs) as a key underpinning of health care reform. ${ }^{4,5}$ PHCOs have been defined as "meso-level" or regional entities responsible for carrying out a range of government primary care reforms that include "focusing on quality improvement, expansion of multidisciplinary teams into general practice, regional integration, information technology adoption, and improved access to care." 4 Smith and Goodwin call these entities "primary care organizations" whose roles are "to improve health outcomes, manage demand and control costs, engage primary care physicians, enable greater integration of health services, develop more accessible services in community and primary care settings, and enable greater scrutiny and assurance of the quality of primary care services." 6 These PHCOs' structure, payments, governance, accountability, and

\footnotetext{
${ }^{1}$ National Academy for State Health Policy, Portland, Maine.
}

(C) The Author(s) 2015; Published by Mary Ann Liebert, Inc. This Open Access article is distributed under the terms of the Creative Commons Attribution Noncommercial License (http://creativecommons.org/licenses/by-nc/4.0/) which permits any noncommercial use, distribution, and reproduction in any medium, provided the original author(s) and the source are credited. 
"name" vary, but expectations to work with primary care practices to improve quality and efficiency outcomes at both the patient and population level are shared ${ }^{5,7}:$ it is this rolehow PHCOs work with primary care practices to improve care delivery - that is the purpose of this comparison study.

In the United States, numerous state governments are in various stages of creating similar kinds of meso-level entities with varying capacity and accountability as part of their primary care reform. For instance, states are developing regionally based organizations, with varying levels of structure, payments, governance, accountability, and "name." ${ }^{, 8}$ Like international PHCOs, many of these organizations are tasked with providing "accountable care." Although some Medicaid organizations may be referred to or named "Accountable Care Organizations" (ACOs), Medicaid ACOs vary widely ${ }^{10}$ and, therefore, some bear little resemblance to Medicare ACOs. ${ }^{11}$ Most notably, the organizations of interest for this study were tasked with working with all eligible providers in an entire region to manage or integrate patient care, were not direct service providers, and met the definition of PHCOs already described., ${ }^{8,9}$

PHCOs are well positioned to work with primary care practices of all sizes and capacity to develop competencies to provide comprehensive, coordinated, and accessible patient-centered care that meets quality, safety, and efficiency outcomes-all attributes associated with highperforming primary care or medical homes. ${ }^{12}$ These core competencies are important for the effective management of patients with chronic illnesses. ${ }^{2}$

The purpose of this paper is to compare and contrast the policy making and implementation experience of publicly financed PHCOs in 3 leading states-Colorado, North Carolina, and Oregon - to an international leader in primary care-Australia ${ }^{3}$ - to learn if PHCOs are focused on the development of high-functioning primary care practices (medical homes) capable of meeting the large majority of their patients' needs. This study sought to surface key policies that enabled PHCOs to deliver on government expectations to strengthen the delivery of primary care services by working with practices on a number of initiatives aligned with medical home principles. These findings have important implications to inform policy decisions in designing new or reforming existing PHCOs as an essential component of an organized, integrated, high-performing health system.

\section{Methods}

\section{Study design and sample}

This 1-year project, conducted from 2014 to 2015, was based in Australia and included 26 semi-structured interviews, half conducted on site and half via telephone, with senior PHCO management, primarily chief executive officers (CEOs) and executive directors. The researcher also reviewed government documents and communicated directly with government officials to understand PHCO objectives and expectations.

For the US, the researcher focused on state implemented PHCOs for the comparison group for 2 main reasons. First, the researcher was interested in government financed PHCOs; second, there have been a significant number of states undergoing delivery reform that have launched mesolevel primary care-based organizations ${ }^{8,9}$ that shared core features of PHCOs that might be informed by this study's findings. The study was limited to states that had PHCOs that met the definitions described in the introduction, were scaled statewide to look at variation between like PHCOs, represented diverse geographic areas from urban to remote, and shared similar scope and objectives. This resulted in the selection of Colorado, North Carolina, and Oregon. Australia was selected because it has more than 20 years of experience of evolving PHCOs, its health system has been consistently ranked as one of the best in the world, ${ }^{1}$ and its geography and PHCO scope provided reasonable comparisons to the US models as seen in Table 1.

As seen in Table 1 , this study sampled approximately $25 \%$ of PHCOs from each study site-15/61 from Australia, 3/7 from Colorado, 4/14 from North Carolina, and 4/16 from Oregon. Using a purposeful sampling approach, the researcher selected PHCOs that were considered to be leaders in developing innovative primary care initiatives and balanced the selection to represent diverse geographical areas. For the 3 states, government officials identified PHCO leaders. In Australia, an expert group of 5 representing federal, academic, and PHCO leaders identified PHCO leaders. All PHCOs contacted to participate in this study consented and all signed a consent form.

\section{Study objectives}

The focus of this study was to compare PHCO models in their capacity to support practices to become high functioning primary care; in other words, meet the attributes of a medical home. Therefore, the interview protocol was organized along domains fundamental to medical homes: comprehensiveness, patient-centeredness, coordination, accessibility, quality and safety, ${ }^{2}$ as well as primary care provider engagement and cost-efficiency. The researcher also was interested in offering policy recommendations; therefore, the last section of the protocol explored government policy enablers and facilitators. (Examples of interview questions are shown in Table 2.) The interview protocol was pretested with 3 PCHOs, revised, and sent out in advance to all interviewees. The Behavioural \& Social Sciences Ethical Review Committee at the University of Queensland in Brisbane, Australia approved the interview protocol.

\section{Data collection}

Data collection methods included the use of on-site and telephone interviews that were audiotaped and transcribed for data analysis. Data collection also included review of government documents from each study site, including request for proposals, invitations to apply, and guidelines for applications, with most documents found on government Web sites and some information provided directly to the researcher by government officials. These documents defined PHCO goals and objectives, core criteria, supports to PHCOs including payment model and infrastructure, and strategies to evaluate PHCO performance. Because of the semi-structured format of the interview, some interviewees did not answer all questions. In those instances, response numbers are given rather than percentages.

\section{Data analysis}

All data sets (transcribed interviews and government documents) were loaded into NVivo10 software (QSR 
Table 1. Characteristics of Study Primary Health Care Organizations

\begin{tabular}{|c|c|c|c|c|}
\hline Type & $\begin{array}{l}\text { Australia } \\
\text { Medicare } \\
\text { Locals } \\
(\mathrm{n}=15 / 61)\end{array}$ & $\begin{array}{c}\text { Colorado } \\
\text { Regional Care } \\
\text { Collaborative } \\
\text { Organizations }(\mathrm{n}=3 / 7)\end{array}$ & $\begin{array}{l}\text { North } \\
\text { Carolina } \\
\text { Networks } \\
(\mathrm{n}=4 / 14)\end{array}$ & $\begin{array}{c}\text { Oregon } \\
\text { Coordinated } \\
\text { Care Organizations } \\
(\mathrm{n}=4 / 16)\end{array}$ \\
\hline Range years in operation & $2-4$ & $2-4$ & $11-16$ & $2-3$ \\
\hline $\begin{array}{l}\text { \# People served* } \\
\text { median } \\
\text { range }\end{array}$ & $\begin{array}{c}497,702 \\
235,182-932,535\end{array}$ & $\begin{array}{c}103,000 \\
90,500-145,000\end{array}$ & $\begin{array}{c}108,817 \\
68,000-135,000\end{array}$ & $\begin{array}{c}36,000 \\
11,000-240,000\end{array}$ \\
\hline $\begin{array}{l}\text { \% Low socioeconomic status } \\
\text { median } \\
\text { range }\end{array}$ & $\begin{array}{c}\text { of population serv } \\
32 \\
2-59\end{array}$ & 100 & 100 & 100 \\
\hline $\begin{array}{l}\text { \# Primary care providers serve } \\
\text { median } \\
\text { range }\end{array}$ & 550 & $\begin{array}{c}236 \\
225-265\end{array}$ & $\begin{array}{c}495 \\
300-1314\end{array}$ & $\begin{array}{c}257 \\
50-1601\end{array}$ \\
\hline $\begin{array}{l}\text { Catchment area (square miles) } \\
\text { median } \\
\text { range }\end{array}$ & $\begin{array}{c}3055 \\
94-520,539\end{array}$ & $\begin{array}{c}6750 \\
875-30,589\end{array}$ & $\begin{array}{c}3359 \\
1623-4479\end{array}$ & $\begin{array}{c}3066 \\
1640-50,000\end{array}$ \\
\hline $\begin{array}{l}\text { Geographic area* } \\
\text { Mostly urban } \\
\text { Mixed urban/rural } \\
\text { Mostly rural } \\
\text { Mixed rural/remote } \\
\text { Mostly remote }\end{array}$ & $\begin{array}{l}7 \\
3 \\
3 \\
1 \\
1\end{array}$ & $\begin{array}{l}1 \\
1 \\
1\end{array}$ & $\begin{array}{l}2 \\
2\end{array}$ & $\begin{array}{l}1 \\
1 \\
1 \\
1\end{array}$ \\
\hline
\end{tabular}

Source/Notes: Author's analysis of data from interview notes and select data from Australia's National Health Performance Authority. Available at: http://www.myhealthycommunities.gov.au/Content/publications/downloads/NHPA_HC_Report_Avoidable_deaths_life_expectancy_ December_2013.pdf.

NOTE: Data for fields marked with asterisk for Australia Medicare Locals were derived from the National Health Performance Authority.

International Pty Ltd, Doncaster, Victoria, Australia). Using a framework analysis, interview data were coded according to the medical home domains described previously. Government documents were coded along 8 domains (governance, authority, scope, objectives, criteria, payment, support for infrastructure, and performance metrics) that had previously been vetted to describe publicly financed accountable care "entities." 13 Within the "criteria domain," government data were further organized into the domains used for the interview data and lined up against the interview data using spreadsheets to compare whether policy expectations translated into on-the-ground implementation.

Where there was overlap, data were coded in more than 1 domain. Frequency counts within each domain identified key themes that were then further organized in spreadsheets. Text searches for key and stemmed words were used for

Table 2. Examples of Primary Health Care Organization (PCHO) Interview Questions

1. Describe some of the strategies undertaken to engage primary care practices to use the resources of your PHCO.

2. Describe any strategies that your PHCO has implemented to support the capacity of primary care practices to meet the large majority of their patients' needs, including mental health, substance abuse, social supports, etc.

3. Has your PHCO implemented any strategies to support primary care practices to provide team-based care including embedding or sharing multidisciplinary staff (eg, nurses, pharmacists, community health workers, mental health counselors) on site or virtually via telehealth? If yes, please describe.

4. Does your PHCO either provide directly or support the capacity of primary care practices to provide any services that enhance health literacy and self-care capabilities for individuals and families? If yes, please describe.

5. How does your PHCO support primary care practices in providing care coordination or helping the patient navigate the health care system?

6. What role, if any, does your PHCO play in supporting communication between primary care practices and other providers, including specialists and hospitals, regarding patient visits, admissions, or discharges?

7. Does your PHCO work with primary care practices to help them improve access to primary care services including shorter waiting times, same-day scheduling, and enhanced evening or weekend appointments?

8. What kind of data and how often does your PHCO provide to primary care practices to inform their quality improvement activities?

9. Has your PHCO provided any incentives for primary care practices to focus on and/or achieve goals to reduce inappropriate utilization of services, such as hospital readmissions, and use of high-cost imaging services, among others? If yes, please describe.

10. Describe the top policy enablers or facilitators that help PHCO to support primary care delivery.

11. Describe the top policy barriers that make it challenging for PHCOs to support primary care delivery. 
each data set to verify that themes were not missed. In addition, government officials and PHCO interviewees from each study site reviewed the draft report.

\section{Results}

\section{Policy context, objectives, and scope}

In Australia, the federal government (Commonwealth) has been evolving PHCOs for more than 23 years, beginning with the Divisions of General Practice. Although the divisions had strong engagement of general practitioners, a government review found considerable variation among the divisions in performance, ${ }^{5}$ which led to the formation of 61 Medicare Locals (MLs) in 2011. MLs were tasked with building on the work of the divisions, improving coordination and integration of primary health care in local communities, and making it easier for patients, especially those with chronic illnesses, to navigate their local health systems. ${ }^{14}$

In Colorado, 7 Regional Care Collaborative (RCCOs) were launched statewide in 2011 after unsuccessful attempts to implement Medicaid managed care, unprecedented growth in costs, and a desire to move toward more value-based purchasing. ${ }^{15}$ In 1998, the North Carolina Department of Health and Human Services, responding to severe budget pressures, received federal permission to launch locally based, "physician-directed" care management systems to target at-risk, high-cost Medicaid patients and meet quality and costs objectives. ${ }^{16}$ In Oregon, faced with a nearly $\$ 2$ billion Medicaid budget deficit, an agreement with the Obama Administration gave the state $\$ 1.9$ billion under terms of slowing cost growth and improving health outcomes to test risk-based Coordinated Care Organizations (CCOs) statewide. ${ }^{17}$

The government objectives that guided the creation of PHCO across the 4 sites shared a similar policy direction: local approaches, integrated and coordinated care, provider support, and improved patient care, as seen in Table 3. In addition, the types of entities that could serve as PHCOs and governance characteristics shared many similarities, with physician-led organizations being the predominant entity. Governance arrangements varied, with PHCOs in Australia and North Carolina being all nonprofit and PHCOs in Colorado and Oregon being a mix of nonprofit and for-profit organizations.

A look at the median values for the 26 study PHCOs shows many similarities in scope, but there are important differences as seen in Table 1. First, although Oregon CCOs were comparatively smaller than the other PHCOs in terms of numbers of patients and providers, they were the only PHCOs held accountable for local health outcomes and costs for their Medicaid population in their catchment area. Second, North Carolina networks have been in operation significantly longer than the other study PHCOs, although Australian MLs evolved from PHCOs that predated North Carolina's networks. Third, the median number of people served by the Australian MLs was nearly half a million, eclipsing the US PHCOs by several hundred thousand. Because all Australians receive national health care coverage through Medicare, an ML's catchment included all people that reside in its area. As a result, the number of people considered low income in the ML catchment areas varied widely, from $2 \%$ to $59 \%$. In the study states, the target population was the Medicaid population, accounting for the substantial differences in population size and the percentage of low-income people served compared to Australia.

\section{Core criteria and PHCO experience}

On paper, the study governments' core criteria shared more similarities than differences with regard to how PHCOs were to support work aligned with medical home domains. For instance, one of the common core criteria was primary care provider engagement in $\mathrm{PHCO}$ or government initiatives to improve primary care delivery. Across the 4 study sites, all PHCO interviewees described a range of common strategies to engage practices that included: peer-to-peer outreach in which PHCOs either contracted with or employed physicians to visit practices to discuss joining initiatives or provide data and give feedback on how to improve practice performance; use of financial incentives; assistance to add multidisciplinary staff for practices to provide comprehensive services; and education and resources that include learning collaboratives, workshops, and evidence-based tools to support continuous quality improvement.

On the ground, as seen in Table 4, PHCO interviewees reported activity in all domains but the intensity of activity varied considerably between study sites in Australia. The key differences across the 4 study PHCOs were improving care coordination, access to care, and reducing unnecessary costs.

Coordinated care. A key objective and core criteria for all PHCOs was coordinating services across various sectors, building on existing systems of care. All PHCOs interviewed described extensive work formalizing agreements between sectors to improve coordination and integration of services. For instance, 10 ML interviewees described extensive work formalizing care pathways between providers and sectors using tools such as HealthPathways ${ }^{18}$ and all North Carolina network interviewees reported collaboration with local hospitals to embed care managers to improve patient discharge transitions.

A key difference in care coordination criteria was that all US PHCOs were required to ensure that care coordination services were provided for targeted patients. All Colorado and North Carolina PHCO interviewees reported hiring, embedding, and often sharing care coordinators at every primary care practice in their catchment area that wanted one and had sufficient numbers of chronically ill Medicaid patients. In Oregon, CCOs described providing practices with added payments so that they could hire their own care coordination staff. In Australia, although most MLs provided some level of care coordination services, it was mostly limited to Aboriginal health services programs.

Accessible services. All PHCOs were expected to expand access to primary care services. The Australia MLs were given funds to take over primary care-based afterhours services initiated by the Commonwealth. All ML interviewees reported implementing after-hours programs by providing incentives for general practices to stay open longer, taking calls and providing face-to-face services as needed, and/or contracting with a deputizing service to provide after-hours care. Nine MLs also reported work with 


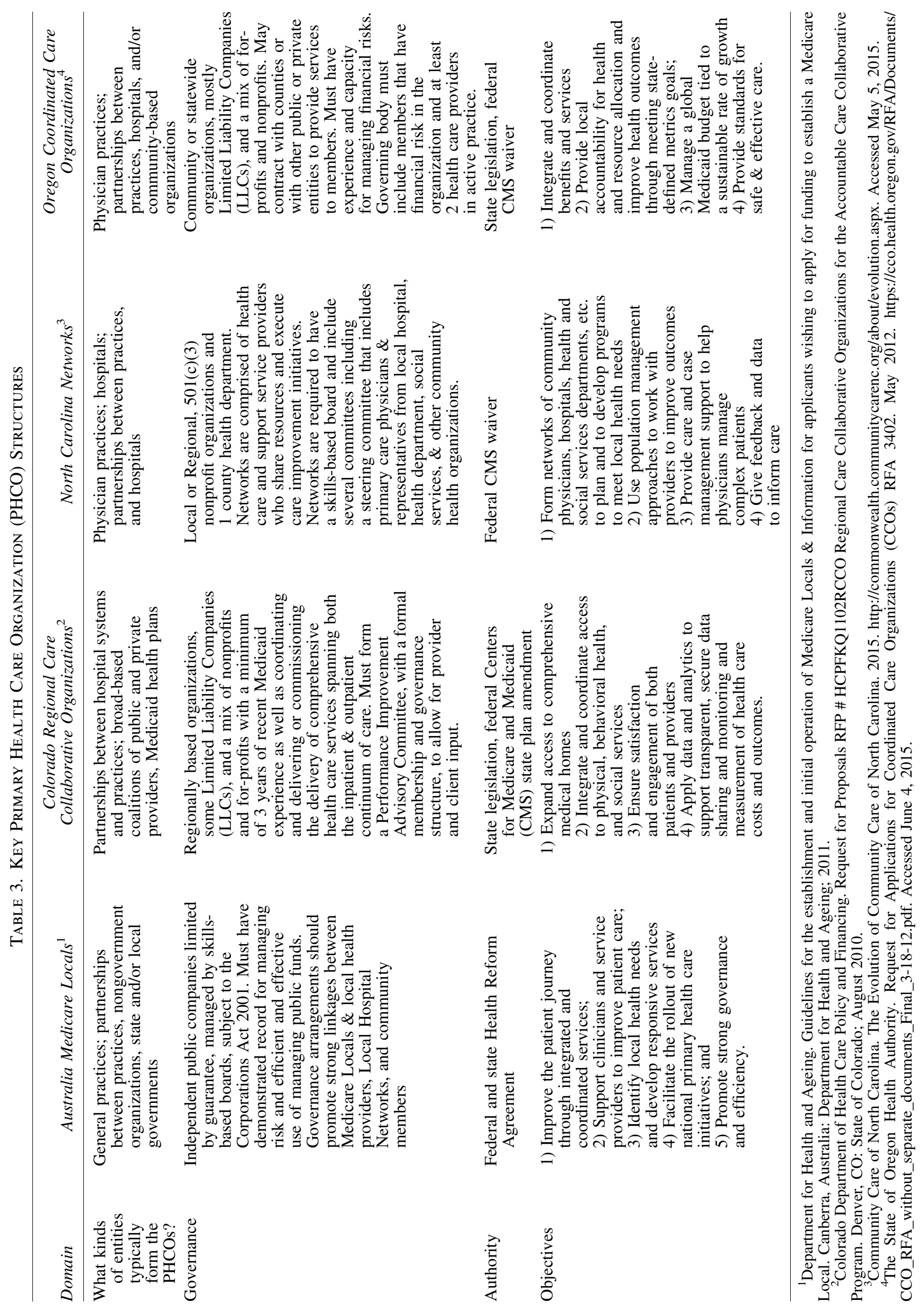


Table 4. Select Primary Health Care Organization (PCHO) Criteria against Reported Level of Activity

\begin{tabular}{|c|c|c|c|c|}
\hline Select medical home activities & $\begin{array}{l}\text { Australia } \\
\text { Medicare } \\
\text { Locals }^{1,2}\end{array}$ & $\begin{array}{c}\text { Colorado Regional } \\
\text { Care Collaborative } \\
\text { Organizations }\end{array}$ & $\begin{array}{c}\text { North } \\
\text { Carolina } \\
\text { Networks }^{4-7}\end{array}$ & $\begin{array}{c}\text { Oregon } \\
\text { Coordinated } \\
\text { Care Organizations }^{8-9}\end{array}$ \\
\hline \multicolumn{5}{|l|}{ Primary Care provider engagement } \\
\hline $\begin{array}{l}\text { Involvement in governance/ } \\
\text { decision making processes }\end{array}$ & All & $\begin{array}{l}\text { All (Core } \\
\text { requirement) }\end{array}$ & $\begin{array}{l}\text { All (Core } \\
\text { requirement) }\end{array}$ & $\begin{array}{l}\text { All (Core } \\
\text { requirement) }\end{array}$ \\
\hline $\begin{array}{l}\text { Use of contracts to engage all } \\
\text { primary care providers }\end{array}$ & Limited & $\begin{array}{l}\text { All (Core } \\
\text { requirement) }\end{array}$ & $\begin{array}{l}\text { All (Core } \\
\text { requirement) }\end{array}$ & $\begin{array}{l}\text { All (Core } \\
\text { requirement) }\end{array}$ \\
\hline Provide education and training & $\begin{array}{l}\text { All (Core } \\
\text { requirement) }\end{array}$ & $\begin{array}{l}\text { All (Core } \\
\text { requirement) }\end{array}$ & $\begin{array}{l}\text { All (Core } \\
\text { requirement) }\end{array}$ & $\begin{array}{l}\text { All (Core } \\
\text { requirement) }\end{array}$ \\
\hline \multicolumn{5}{|l|}{ Comprehensive care } \\
\hline $\begin{array}{l}\text { Coordinate access } \\
\text { to mental health services }\end{array}$ & $\begin{array}{l}\text { All (Core } \\
\text { requirement) }\end{array}$ & $\begin{array}{l}\text { All (Core } \\
\text { requirement) }\end{array}$ & $\begin{array}{l}\text { All (Core } \\
\text { requirement) }\end{array}$ & $\begin{array}{l}\text { All (Core } \\
\text { requirement) }\end{array}$ \\
\hline $\begin{array}{l}\text { Integrate mental health providers } \\
\text { in primary care practices }\end{array}$ & Most & Most & Limited & $\begin{array}{l}\text { All (Core } \\
\text { requirement) }\end{array}$ \\
\hline $\begin{array}{l}\text { Provide resources for } \\
\text { team-based care }\end{array}$ & All & All & All & All \\
\hline Patient/family role & $\begin{array}{l}\text { All (Core } \\
\text { requirement) }\end{array}$ & $\begin{array}{l}\text { All (Core } \\
\text { requirement) }\end{array}$ & $\begin{array}{l}\text { All (Core } \\
\text { requirement) }\end{array}$ & $\begin{array}{l}\text { All (Core } \\
\text { requirement) }\end{array}$ \\
\hline \multicolumn{5}{|l|}{ Coordinated care } \\
\hline $\begin{array}{l}\text { Establish partnerships } \\
\text { across care spectrum }\end{array}$ & $\begin{array}{l}\text { All (Core } \\
\text { requirement) }\end{array}$ & $\begin{array}{l}\text { All (Core } \\
\text { requirement) }\end{array}$ & $\begin{array}{l}\text { All (Core } \\
\text { requirement) }\end{array}$ & $\begin{array}{l}\text { All (Core } \\
\text { requirement) }\end{array}$ \\
\hline $\begin{array}{l}\text { Work with hospital } \\
\text { and specialty services }\end{array}$ & $\begin{array}{l}\text { All (Core } \\
\text { requirement) }\end{array}$ & $\begin{array}{l}\text { All (Core } \\
\text { requirement) }\end{array}$ & $\begin{array}{l}\text { All (Core } \\
\text { requirement) }\end{array}$ & $\begin{array}{l}\text { All (Core } \\
\text { requirement) }\end{array}$ \\
\hline Use of care coordinators & Most & $\begin{array}{l}\text { All (Core } \\
\text { requirement) }\end{array}$ & $\begin{array}{l}\text { All (Core } \\
\quad \text { requirement) }\end{array}$ & $\begin{array}{l}\text { All (Core } \\
\text { requirement) }\end{array}$ \\
\hline \multicolumn{5}{|l|}{ Accessible services } \\
\hline $\begin{array}{l}\text { Work with practices } \\
\text { to improve scheduling }\end{array}$ & Most & All & All & All \\
\hline After-hours face-to-face urgent care & $\begin{array}{l}\text { All (Core } \\
\text { requirement) }\end{array}$ & $\begin{array}{l}\text { Most (Core } \\
\text { requirement) }\end{array}$ & Limited & $\begin{array}{l}\text { Most (Core } \\
\text { requirement) }\end{array}$ \\
\hline \multicolumn{5}{|l|}{ Quality and Safety } \\
\hline $\begin{array}{l}\text { Clinical data feedback to practices } \\
\text { to support evidence-based medicine }\end{array}$ & $\begin{array}{l}\text { Most (Core } \\
\text { requirement) }\end{array}$ & $\begin{array}{l}\text { All (Core } \\
\text { requirement) }\end{array}$ & $\begin{array}{l}\text { All (Core } \\
\text { requirement) }\end{array}$ & $\begin{array}{l}\text { All (Core } \\
\text { requirement) }\end{array}$ \\
\hline $\begin{array}{l}\text { Quality improvement teams } \\
\text { to work with practices }\end{array}$ & All & All & All & All \\
\hline \multicolumn{5}{|l|}{ Cost-efficient care } \\
\hline $\begin{array}{l}\text { Financial incentives for practices } \\
\text { to focus on utilization }\end{array}$ & Limited & All & None & All \\
\hline Cost data to practices & Limited & $\begin{array}{l}\text { All (Core } \\
\text { requirement) }\end{array}$ & $\begin{array}{l}\text { All (Core } \\
\text { requirement) }\end{array}$ & $\begin{array}{l}\text { All (Core } \\
\text { requirement) }\end{array}$ \\
\hline $\begin{array}{l}\text { Targeted case management } \\
\text { for high-cost patients }\end{array}$ & Limited & All & All & All \\
\hline
\end{tabular}

${ }^{1}$ Department for Health and Ageing. Guidelines for the establishment and initial operation of Medicare Locals \& Information for applicants wishing to apply for funding to establish a Medicare Local. Canberra, Australia: Department for Health and Ageing; 2011.

2Department for Health and Ageing. Medicare Locals Operational Guidelines. Canberra, Australia: Australian Government; April 2013.

${ }^{3}$ Colorado Department of Health Care Policy and Financing. Request for Proposals RFP \# HCPFKQ1102RCCO Regional Care Collaborative Organizations for the Accountable Care Collaborative Program. Denver, CO: State of Colorado; 2010 August.

${ }^{4}$ North Carolina Department of Health and Human Services Division of Medical Assistance. Amendment to the North Carolina's waiver under Section 1915 (b)(1) of the Social Security Act to include Community Care Plan Access II. Raleigh, NC: State of North Carolina; January 28, 1998.

${ }^{5}$ North Carolina Department of Health and Human Services. Access II and III Community Care Plans: Business Plan. Raleigh, NC: State of North Carolina; 2000 January.

${ }^{6}$ Community Care of North Carolina. Community Care of North Carolina (CCNC) Program Start-Up / Expansion Notebook. Raleigh, NC: CCNC;2005.

${ }^{7}$ Community Care of North Carolina. A history of CCNC. https://http://www.communitycarenc.org/about-us/history-ccnc-rev/. Accessed June 4, 2015.

${ }^{8}$ Oregon Health Policy Board. Coordinated Care Organizations Implementation Proposal. January 2012. https://cco.health.oregon.gov/ Documents/cco-implementation-proposal.pdf. Accessed June 4, 2015.

${ }^{9}$ Oregon Health Authority. Request for Applications for Coordinated Care Organizations (CCOs) RFA 3402. May 2012. https:// cco.health.oregon.gov/RFA/Documents/CCO_RFA_without_separate_documents_Final_3-18-12.pdf. Accessed June 4, 2015.

Source/Notes: Author's analysis of data from interview notes and from government documents listed above. NOTE: Core requirement means expectation of PHCOs as stated in government documents for prospective PHCOs. Most means $\geq 50 \%$ (limited means <50\%) determined from number of PHCO interviewees from each study site who reported some level of activity in this domain; this could range from activity with a few practices to activity with many practices. 
a limited number of practices to expand access to appointments for same-day scheduling and reduced waiting times.

US interviewees reported limited work with practices to provide after-hours face-to-face urgent care. After-hours coverage tended toward 24 hour/7 day telephonic triage support. All reported extensive work with a wide number of practices to expand access to timely or same-day primary care appointments through medical home certification processes.

Cost-efficient care. Each government recognized the role of PHCOs in improving delivery system efficiency and reducing unnecessary cost.

ML criteria focused on "more efficient utilization of health and administrative resources" and expectations to contribute to "efficiency and equity across health sectors in the local area."19 Therefore, MLs focused on streamlining referral mechanisms and coordinating care across sectors to reduce wait times for specialty care, unplanned admissions, and/or emergency department presentations using the tools mentioned previously (eg, HealthPathways). Work to identify high-cost, high-needs patients in the care system and target care management resources was more limited. In Australia, data on hospitalization and specialty care utilization resides with the state and territory governments, and access to these data has been a challenge for MLs in identifying patients and practices that require added resources. Several ML interviewees reported plans or projects under way to work with their state or territory governments and local hospital networks to improve data collection and sharing.

In the United States, improving work at the systems level was widely reported, but in addition, all US PHCO interviewees were focused on reducing costs through the identification and care management of high-needs, high-cost patients. All US PHCOs reported receiving monthly or quarterly claims data reports from their statewide analytics center that described PHCO performance on costs and quality metrics, allowing them to see opportunities for interventions. Colorado and North Carolina PHCOs also received providerand patient-level metrics. Oregon CCO interviewees reported the development of in-house capacity to perform their own patient and provider analytics.

\section{Policy levers and PHCO experience}

Interviewees were asked to rank their government's level of priority placed on PHCOs to focus efforts and resources on supporting high-functioning primary care providers. The responses were squarely split along international lines with all US PHCOs giving their state governments a high ranking and a majority of Australian MLs giving the Commonwealth a low ranking. Despite similar policy objectives, the differences in interviewees' responses were attributed to government direction and the availability of 2 policy levers needed to support transformation work: payment model and performance framework.

Payment model. The Australia ML payment model is distinct from the 3 study states. The MLs' primary payment initially came in 3 categories: core (general administrative overhead), flexible funding (activities to support a range of primary care initiatives and services to meet local health needs), and program funding (implementing Commonwealth priority programs.) The payment amounts were determined based on the relative cost differences of operating MLs across the country, accounting for unique characteristics of the catchment area and population and weighted to take into account such factors as health inequities, socioeconomic status, age profiles, among others. To provide a rudimentary comparison for context, one urban ML with a population of approximately 908,000 patients reported a per annum budget of $\$ 40$ million, which would translate to about $\$ 44$ per member per year or $\$ 3.70$ per member per month (PMPM).

In the 3 study states, payment to the PHCOs was calculated on a PMPM basis and was to be used to identify chronically ill and other high-risk populations and work with practices to improve the delivery of services to these groups to meet state health objectives. At the outset, RCCOs in Colorado received \$13 PMPM; in North Carolina, networks received $\$ 13.72$ for Aged, Blind, and Disabled populations and \$3.72 for all others. In Oregon, CCOs received a capitated PMPM portion for the services formerly provided by physical health plans, behavioral health (mental health and substance abuse) organizations, and dental care organizations that was tied to a $3.4 \%$ fixed rate of growth.

Colorado and Oregon PHCO payment models also included a performance-based component. In Colorado, \$1 PMPM was withheld and in Oregon, 2\% (a year later, 3\%) was withheld to be "earned back" if the PHCOs met the performance indicators summarized in Table 5. All PHCOs in Colorado and Oregon described voluntarily passing through a portion or all money earned back to practices that performed well. Neither Australia nor North Carolina used performance-based payments for their PHCOs.

Another PHCO payment model distinction was that both Colorado and North Carolina Medicaid programs also provided a PMPM payment to primary care providers who contracted with their PHCOs to meet program objectives. The payment to the primary care providers, in addition to fee-for-service rates, was \$5 PMPM for caring for Aged, Blind and Disabled populations and $\$ 2.50$ for all others in North Carolina and \$4 PMPM in Colorado. In addition, Colorado also held back $\$ 1$ of the $\$ 4$ PMPM for providers to earn back when their RCCO performed well on the key performance indicators.

A majority of ML interviewees responded that their payment model provided insufficient funding levels, and 93\% described a lack of flexibility to use their funding as chief barriers in their efforts to support high-functioning primary care practices. For an example, one ML CEO described how out of a $\$ 40$ million budget, only $\$ 900,000$ was allowed for flexible spending. Only 1 interviewee across the 3 states described the funding level as insufficient. None of the US interviewees described their current payment model as inflexible. North Carolina and Oregon interviewees described the Medicaid-only focus of their state's initiative as being of insufficient scale to effect broad-scale primary care transformation.

Performance framework. Both Colorado and North Carolina governments contracted with private entities to provide data and analytics through a Web portal to support PHCOs (and primary care providers) in meeting quality and cost objectives. These data analytic centers used claims data 


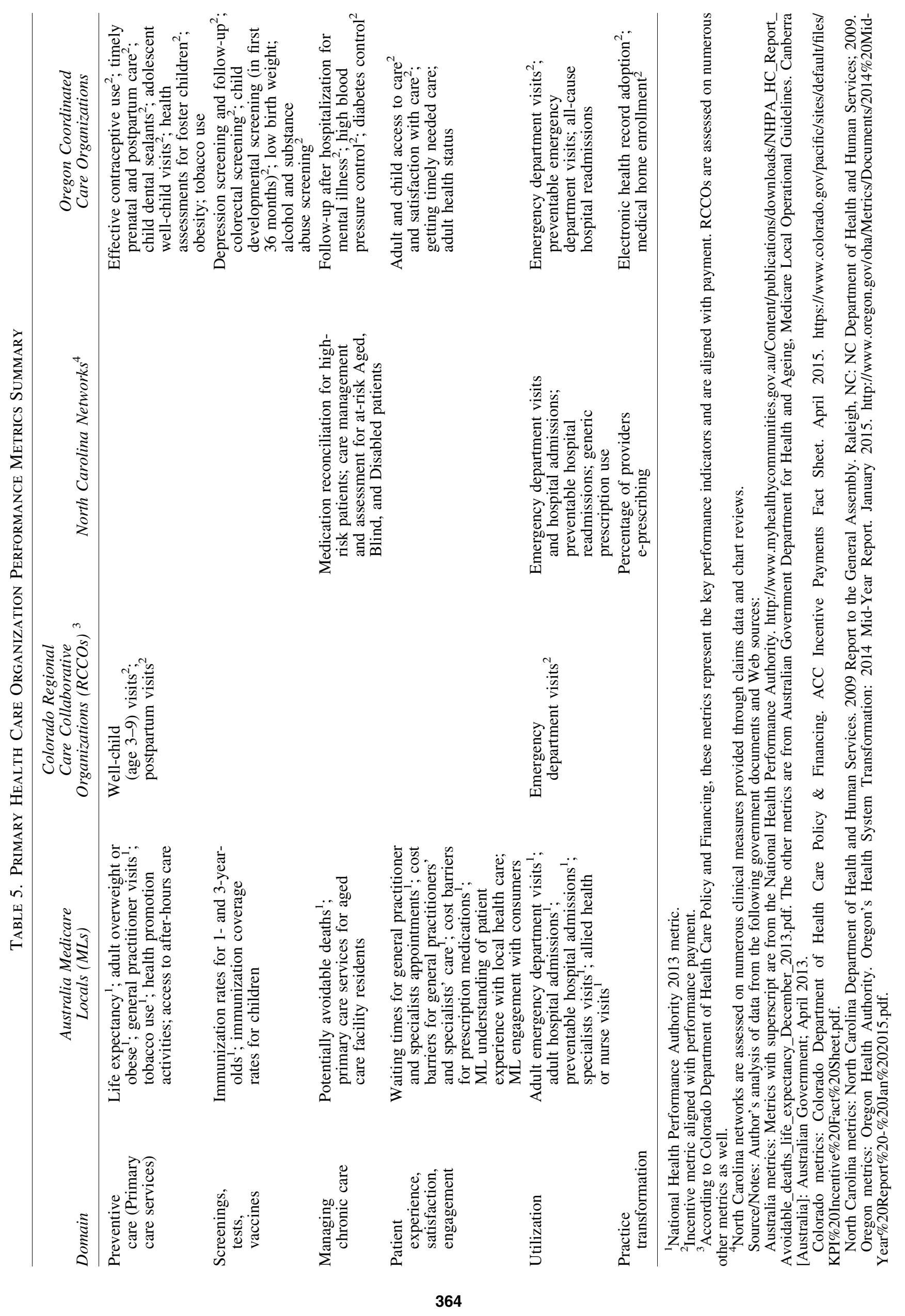


to provide trending analysis, population management, quality, cost of care, and in North Carolina, predictive modeling reports on a quarterly and on-demand basis. Reports also compared performances of PHCOs as well as the providers. North Carolina Informatics Center data also were supplemented by clinical data provided through regular chart audits. In addition, North Carolina networks and providers had access to real-time inpatient and emergency admission, discharge, and transfer data from most hospitals in the state. $^{20}$

In Oregon, the Health Authority Office of Health Analytics provided CCOs with claims data reports on progress toward meeting performance metrics on a monthly basis. Twice annually, the Oregon Health Authority publicly released CCO performance metrics described in Table 5, as well as cost and utilization data. In addition, Oregon implemented a centralized registry known as the Emergency Department Information Exchange that provided real-time admission and discharge information to CCOs and health providers. $^{21}$

In Australia, the National Health Performance Authority was charged with monitoring the performance of MLs including comparing high and low performers. ${ }^{19}$ The Authority released numerous reports about the health of the population within each ML catchment area to help inform service delivery, although it is important to note that the data used generally predated the ML's existence. ${ }^{22}$ MLs did not receive regular feeds of Medicare claims data and analytic support from federal, state, or territory governments to inform ML or provider performance and, therefore, most MLs pursued other data collection strategies. Thirteen funded the use of a clinical auditing tool for interested general practices that extracted data from practices' electronic health records, "cleansed" it, and fed it back to practices; 3 described developing their own data warehouse or portal for the purpose of supporting general practice quality improvement activities.

Six ML interviewees cited the lack of data collection, analytics, and/or "connectivity" of data between the 2 levels of governments as major barriers in supporting practice performance. In contrast, all North Carolina networks interviewees described the data and analytical support from its Informatics Center as a major asset. Despite the 4-6 months claims data lag described by one Colorado interviewee, all RCCO interviewees found the statewide data center helpful to their work. Three Oregon CCO interviewees described the Emergency Department Information Exchange as a valuable resource.

The kinds of PHCO performance metrics selected varied dramatically across the 4 study sites as seen in Table 5 . The only metric that all 4 PHCOs shared was emergency department utilization.

\section{Discussion}

This study sought to compare and contrast the policy making and implementation experience of PHCOs found in Australia, Colorado, North Carolina, and Oregon; each government has made significant investments in PHCOs with expectations to improve health system efficiency and to support high-functioning primary care practices. This study found PHCOs in each of the 4 sites that were meeting government expectations to support primary care transformation, but across the board, the US PCHOs demonstrated more robust and consistent activity. These activities were linked to the use of a flexible payment model and a performance framework. Although most Australia MLs reported some activities to support high-functioning primary care, there were considerable differences in their level of effort with some supporting many practices, but most supporting just a few-findings consistent with a 2014 government-commissioned report. ${ }^{23}$ The study findings aimed to make policy recommendations to help inform future and current policy making regarding using PHCOs as vehicles to accelerate practice transformation efforts.

\section{PHCOs need scale to tilt the transformation scale}

Because of single payer coverage in Australia, the MLs have scale that the US PHCOs need to effect broad-scale primary care transformation. Several PHCO interviewees in the United States described lacking the leverage to influence or engage primary care practices that see a limited number of Medicaid patients. This finding is consistent with those found in other literature related to multi-payer medical home payment reform. ${ }^{24,25}$ Multi-payer financing of PHCOs would address this limitation. In 2014, Oregon CCOs allowed state employees to select health plans that included CCOs, ${ }^{26}$ and there are future efforts to allow public education employees to opt in. North Carolina has had some success attracting other payers and purchasers to contract for network services to care for privately insured patients, holding promise for further expansion. ${ }^{27}$ Negotiating the inclusion of public employees and/or private payers and purchasers into the $\mathrm{PHCO}$ fold would be a significant gain in scale for any US-based PHCOs by giving them a broader reach to accelerate practice transformation efforts.

\section{Alignment of payment and performance measures for PHCOs in coordination with other sectors is essential to meet health system goals}

Colorado and Oregon introduced progressive PHCO and provider payment models that offer strategies for policy makers developing new or reforming existing PHCOs. Both states developed payment models aligned with performance metrics for both PHCOs and providers to meet together. Oregon's PHCO model, the newest model included in this study, took an additional step in the payment model evolution and provided its CCOs with a global budget to create community-based accountable care organizations. Both states have reported early wins in lowering cost growth and improving quality with these models. ${ }^{28,29}$

In Australia the split in financing between primary care (Commonwealth) and hospital and specialty care (states and territories) and the lack of data sharing across sectors have created barriers to designing a PHCO payment model aligned with a performance framework. The states and territories in Australia were receiving "activity based" 14 or volume-based funding from the Commonwealth and there was little incentive to coordinate with PHCOs to reduce unnecessary costs. Developing a coordinated data collection strategy and sharing this information across sectors is foundational to guiding activities related to the development of a payment model with goals to reduce per person and per 
capita costs. ${ }^{30}$ Changing the payment model to create the right mix of incentives that result in cross-system collaboration with the PHCOs is no easy feat, but developing a common data collection strategy would be an important first step for the Commonwealth to promote consistent performance between its PHCOs, cross-sector collaboration, and meet health care objectives.

\section{Developing PHCO capacity is an iterative process}

Policies need to adapt to emerging challenges such as rising numbers of aging and chronically ill populations as well as emerging payment models and tools. Both Australia and North Carolina have supported PHCOs for more than 20 years without varying their payment models significantly. The original design for the 1998 North Carolina pilots expected networks "to move toward partial or full risk bearing entities" once infrastructure was developed and experience was gained. ${ }^{16}$ Although the North Carolina networks have demonstrated improved health and cost outcomes over the years for network patients, with the most recent report by the North Carolina auditor, ${ }^{31}$ the current legislature is looking for newer strategies to rein in Medicaid spending. ${ }^{32}$

In Australia, PHCOs have a new direction beginning July 2015 , on the heels of an unfavorable government review of the MLs. ${ }^{23}$ With new criteria and redrawn catchment areas, 31 Primary Health Networks (PHNs) have been selected to replace the $61 \mathrm{MLs}{ }^{33}$ The PHNs have 2 program objectives: improve the "efficiency and effectiveness of medical services," especially for those at risk, and improve "coordination of care" at the patient level through support of general practices. ${ }^{34}$ The funding model for PHNs has a stronger focus on PHNs "commissioning" services, thereby providing more flexible funds for local service contracting. PHN operating guidelines also described the development of "innovation and incentive funding" and a "National Primary Health Care Performance Framework." 34 Both levers, if aligned with objectives, will improve consistency in focus and performance between PHNs. In addition, Australia has numerous assets that could significantly accelerate primary care system transformation-assets that would be a boon to the efforts in the United States as well-that include health care identifiers (national unique digital number assigned to patients and providers) $^{35}$ and a nationwide launch of personal e-health records. ${ }^{36}$ Both have important implications for tracking patients and coordinating care across the health sectors.

\section{Limitations}

In addition to focusing on supporting high-functioning primary care practices, Australian PHCOs traditionally have had a broader mandate than their comparators in the United States to focus on population health activities for the entire population in their catchment area. Therefore, the activities that MLs are able to undertake to support primary care capacity may compete with population health activities.

The responses describing the PHCO implementation experience are limited to the views of the PHCO interviewees and may not identify all potential areas of activity. A review of government documents may have been subject to author bias, particularly concerning coding of data and interpretation. To address this issue, government officials from each study site reviewed the draft findings.
The medical home is a model of care that has been widely tested in the United States. Although familiar with the medical home model, for interviews in Australia, the term "highfunctioning primary care providers" was interchanged with medical home.

\section{Conclusion}

PHCOs have been an important vehicle for governments in Australia, Colorado, North Carolina, and Oregon and other nations across the world to roll out initiatives aimed at strengthening the primary care foundation. Developing capacity in primary care practices to care for the needs of chronically ill populations requires support that PHCOs are well positioned to provide-given the right levers. Clear policy directives and the combination of flexible and incentive funding aligned with a performance framework are necessary levers to ensure that PHCOs work uniformly toward and achieve macro-level health system goals to support primary care capacity while being nimble enough to meet the unique needs of their provider and patient communities.

\section{Author Disclosure Statement}

Ms. Takach declared no conflicts of interest with respect to the research, authorship, and/or publication of this article. This research was supported through a fellowship funded by The Commonwealth Fund and the Australia Department of Health.

\section{References}

1. OECD. Health at a Glance 2013: OECD Indicators. http:// dx.doi.org/10.1787/health_glance-2013-en. Accessed June 3, 2015.

2. Bodenheimer T. Coordinating care-a perilous journey through the health care system. NEJM. 2008;358:10641071.

3. Davis K, Stremikis K, Squires D, Schoen C. Mirror, Mirror On The Wall. How the Performance of the U.S. Health Care System Compares Internationally. 2014 Update. http:// www.commonwealthfund.org/ /media/files/publications/ fund-report/2014/jun/1755_davis_mirror_mirror_2014.pdf. Accessed June 3, 2015.

4. Nicholson C, Jackson CL, Marley JE, Wells R. The Australian experiment: how primary health care organizations supported the evolution of a primary health care system. J Am Board Fam Med. 2012;25:S18-S26.

5. Smith J, Sibthorpe B. Divisions of general practice in Australia: how do they measure up in the international context? Aust New Zealand Health Policy. 2007;4:15.

6. Smith J, Goodwin, N. Towards Managed Primary Care: The Role and Experience of Primary Care Organizations. Aldershot, England: Ashgate Publishing; 2006.

7. Oliver-Baxter JB, Bywood P, Brown L. Integrated care: What policies support and influence integration in health care across New Zealand, England, Canada and the United States? Report 2; 2013. http://www.phcris.org.au/phplib/ filedownload.php?file=/elib/lib/downloaded_files/publications/ pdfs/phcris_pub_8414.pdf. Accessed September 3, 2015.

8. Centers for Health Care Strategies, Inc. Medicaid Accountable Care Organization Learning Collaborative. http://www .chcs.org/project/medicaid-accountable-care-organizationlearning-collaborative-phase-iii/. Accessed June 3, 2015.

9. Takach M, Buxbaum, J. Care Management for Medicaid Enrollees Through Community Health Teams. 2013. http:// 
www.commonwealthfund.org/publications/fund-reports/2013/ may/care-management. Accessed September 3, 2015.

10. Centers for Health Care Strategies, Inc. Comparing State Medicaid Accountable Care Organization Governance Models. http://www.chcs.org/media/ACO-Governance-Matrix_Final_ 072415.pdf. Accessed September 25, 2015.

11. Centers for Medicare and Medicaid Services. Accountable Care Organizations (ACO). Updated January 6, 2015. https://www.cms.gov/Medicare/Medicare-Fee-for-ServicePayment/ACO/index.html. Accessed September 25, 2015.

12. Agency for Healthcare Research and Quality. Patient Centered Medical Home Resource Center: Defining the PCMH. http://pcmh.ahrq.gov/page/defining-pcmh. Accessed May 4, 2015.

13. Stanek M, Takach M. The essential role of states in financing, regulating, and creating accountable care organizations. http://www.nashp.org/sites/default/files/The_Essential_Role_ of_States_in_Financing_final.pdf. Accessed May 4, 2015.

14. Council of Australian Governments. National Health Reform Agreement. http://www.federalfinancialrelations.gov .au/content/npa/health_reform/national-agreement.pdf. Accessed May 4, 2015.

15. Colorado Department of Health Care Policy and Financing. The Accountable Care Collaborative. https://www.colorado .gov/pacific/sites/default/files/Overview of the ACC Program.pdf. Accessed May 4, 2015.

16. North Carolina Department of Health and Human Services Division of Medical Assistance. Amendment to the North Carolina's waiver under Section 1915 (b)(1) of the Social Security Act to include Community Care Plan Access II. Raleigh, NC: State of North Carolina; January 28, 1998.

17. Johnson K. Experiment in Oregon gives Medicaid very local roots. New York Times; April 12, 2013. http://www.nytimes .com/2013/04/13/us/oregon-experiments-with-localizedmedicaid.html?_r=0. Accessed June 3, 2015.

18. Canterbury District Health Board. HealthPathways. http://www .cdhb.health.nz/Hospitals-Services/Health-Professionals/Pages/ Health-Pathways.aspx. Accessed May 4, 2015.

19. Department of Health and Ageing. Medicare Locals Operational Guidelines. Canberra, Australia: Australian Government; April 2013.

20. Community Care of North Carolina. Information support for patient-centered care. https://ic.n3cn.org/. Accessed May 29, 2015.

21. Oregon Health Leadership Council. Emergency department information exchange. http://www.orhealthleadershipcouncil.org/ our-current-initiatives/emergency-department-informationexchange-edie. Accessed May 5, 2015.

22. National Health Performance Authority. MyHealthyCommunities. http://www.myhealthycommunities.gov.au/. Accessed June 3, 2015.

23. Horvath J. Review of Medicare Locals: Report to the Minister for Health and Minister for Sport. March 4, 2014. http:// www.health.gov.au/internet/main/publishing.nsf/Content/ review-medicare-locals-final-report. Accessed October 23, 2015.

24. Takach M, Townley C, Yalowich R, Kinsler S. Making multipayer reform work: what can be learned from medical home initiatives. Health Aff. 2015;34:662-672.
25. Rajkumar R, Conway PH, Tavenner M. CMS-engaging multiple payers in payment reform. JAMA. 2014;311: 1967-1968.

26. Hoffman H. State worker insurance premiums cheaper next year. June 2014. http://www.statesmanjournal.com/story/news/ politics/state-workers/2014/06/17/state-worker-insurancepremiums-cheaper-next-year/10714099/. Accessed June 3, 2015.

27. Trapp D. North Carolina medical home program extended to private, state workers. September 2011. http://www.amednews .com/article/20110912/government/309129956/6/. Accessed May 3, 2015.

28. Colorado Department of Health Care Policy and Financing. Creating a Culture of Change. Accountable Care Collaborative: 2014 Annual Report. https://www.colorado.gov/ pacific/sites/default/files/Accountable Care Collaborative 2014 Annual Report.pdf. Accessed June 3, 2015.

29. Oregon Health Authority. Oregon's Health System Transformation: 2014 Midyear Report. January 2015. http:// www.oregon.gov/oha/Metrics/Documents/2014 Mid-Year Report - Jan 2015.pdf. Accessed June 3, 2015.

30. Fisher ES, Shortell SM, Kreindler SA, Van Citters AD, Larson BK. A framework for evaluating the formation, implementation, and performance of accountable care organizations. Health Aff. 2012;31:2368-2378.

31. Office of the State Auditor. Community Care of North Carolina. Financial Related Audit August 2015. http:// www.ncauditor.net/EPSWeb/Reports/FiscalControl/FCA2014-4445.pdf. Accessed September 8, 2015.

32. Haban R. How do you solve a problem like Medicaid? North Carolina Health News; June 9, 2014 http://www .northcarolinahealthnews.org/2014/06/09/how-do-you-solvea-problem-like-medicaid/. Accessed June 3, 2015.

33. Ley S. New primary health networks to deliver better local care. Last updated April 2015. http://www.health.gov.au/ internet/ministers/publishing.nsf/Content/health-mediarelyr2015-ley036.htm. Accessed May 3, 2015.

34. Australian Government, Department of Health. Primary Health Networks: Grant Programme Guidelines. 2014. http:// www.health.gov.au/internet/main/publishing.nsf/Content/ 53A642596DABB8BFCA257DDD00106EAD/\$File/guide lines.pdf. Accessed October 23, 2015.

35. Australian Government, Department of Human Services. Healthcare Identifiers Service. http://www.humanservices .gov.au/customer/services/medicare/healthcare-identifiersservice. Accessed June 15, 2015.

36. Australian Government, Department of Health. Welcome to eHealth.gov.au. Last updated October 2015. http://www .ehealth.gov.au/internet/ehealth/publishing.nsf/content/home. Accessed June 3, 2105.

Address correspondence to: Ms. Mary Takach National Academy for State Health Policy 10 Free Street Portland, ME 04101

E-mail: mtakach@nashp.org 